\title{
Polifenoles Totales, Antocianinas y Capacidad Antioxidante (DPPH y ABTS) durante el procesamiento del licor y polvo de cacao
}

\section{Total polyphenols, anthocyanins and antioxidant capacity (DPPH and ABTS) during processing of cocoa liquor and cocoa powder}

\author{
Chávez Rivera Ronald Eduardo y Ordoñez Gómez, Elizabeth Susana, \\ Universidad Nacional Agraria de la Selva, Apartado 156
}

DOI: https://doi.org/10.33017/RevECIPeru2013.0006/

\section{Resumen}

El presente trabajo de investigación se desarrolló en los laboratorios del (CIPNA - CIDBAM) - UNAS. Los objetivos fueron: cuantificar el contenido de polifenoles totales, antocianinas y determinar la capacidad antioxidante por su capacidad de inhibir radicales libres 1,1-diphenyl-2-picrilhydrazyl (DPPH) y ácido 2,2azinobis(3etilbenzotiazoline)-6-acidosulfonico (ABTS)durante el proceso del licor de cacao y polvo de cacao. Las muestras fueron molidas y desgrasadas por el método Folch. Se preparó extractos hidroalcohólicos que consistió en pesar $10 \mathrm{~g}$ de cacao en $100 \mathrm{~mL}$ (agua/etanol 50:50v/v), macerado por $24 \mathrm{~h}$, filtrado y centrifugado a $10000 \mathrm{rpm} / 10 \mathrm{~min} / 4^{\circ} \mathrm{C}$. Los resultados fueron analizados mediante el diseño completo al azar (DCA) y el diseño de bloques completo al azar (DBCA), en los tratamientos donde hubo diferencia estadística se aplicó la prueba de Tukey $(p<0,05)$, utilizando el programa SAS versión 9.0. Para analizar todos los tratamientos de manera conjunta se utilizó el análisis multivariado con componentes principales, utilizando el programa estadístico InfoStat versión 2011. El mayor contenido de polifenoles totales durante el procesamiento del licor de cacao y polvo de cacao fue en el grano $6,394 \pm 0,095 \mathrm{~g}$ EAG/100 g y el menor fue para el grano molido $4,036 \pm 0,105 \mathrm{~g} \mathrm{EAG} / 100 \mathrm{~g}$. El mayor contenido de antocianinas fue en el grano $1,490 \pm 0,043 \mathrm{mg}$ cianidina-3glucósido/g y el menor fue para el grano molido 0,074 $\pm 0,003 \mathrm{mg}$ cianidina-3-glucósido/g. y la mayor capacidad de inhibición del radical DPPH fue IC50=51,158 $\pm 0,117 \mu \mathrm{g} / \mathrm{mL}$ y la mejor capacidad de inhibir del radical $A B T S$ fue $I C 50=34,918 \pm 0,054 \mu \mathrm{g} / \mathrm{mL}$.

Descriptores: cacao, polifenoles, antocianinas, antioxidante, DPPH, ABTS 236

\section{Abstract}

This research was developed in the laboratories of (CIPNA - CIDBAM) - UNAS. The objectives were to quantify the content of total polyphenols, anthocyanins and to determine their antioxidant capacity by their ability to inhibit free radicals 1,1-diphenyl-2-picrilhydrazyl (DPPH) and 2,2 - azinobis (3etilbenzotiazoline)-6acidosulfonic (ABTS) during the process of cocoa liquor and cocoa powder. The samples were ground and defatted by the Folch method. Hydroalcoholic extracts were prepared by weighing $10 \mathrm{~g}$ of cocoa in $100 \mathrm{~mL}$ (water / ethanol 50:50 v / v), macerating it for $24 \mathrm{~h}$, filtering and centrifuging at $10000 \mathrm{rpm} / 10 \mathrm{~min} / 4^{\circ} \mathrm{C}$. The results were analyzed using a complete randomized design (CRD) and a complete randomized block design (CRBD), and in the treatments with statistical differences a Tukey test $(p<0.05)$ was used using SAS version 9.0. To analyze all treatments in conjunction a principal component multivariate analysis was used using the statistical software InfoStat version 2011. The highest content of total polyphenols in the process of making cocoa liquor and cocoa powder was found in the grain with $6.394 \mathrm{~g} \pm 0.095 \mathrm{~g} \mathrm{EAG} / 100 \mathrm{~g}$ and the lowest was found in the grounded grain with $4.036 \pm 0.105 \mathrm{~g} \mathrm{EAG} / 100 \mathrm{~g}$. The highest content of anthocyanins was in the grain with $1.490 \pm 0.043 \mathrm{mg}$ cyanidin-3-glucoside/g and the lowest was in the grounded grain with $0.074 \pm$ 
$0.003 \mathrm{mg}$ cyanidin-3-glucoside/g and the greatest inhibitory capacity for the DPPH radical was IC50 $=51.158$ $\pm 0.117 \mu \mathrm{g} / \mathrm{mL}$ and the greatest capacity to inhibit the ABTS radical was IC50 $=34.918 \pm 0.054 \mu \mathrm{g} / \mathrm{mL}$.

Keywords: Cocoa, poly-phenols, anthocyanins, antioxidant, DPPH, ABTS 235

\section{Introducción}

Desde hace más de dos siglos, el cacao en grano se ha destacado como un rubro de gran importancia comercial en el ámbito mundial, ya que éste es utilizado como materia prima para la obtención de diversos productos de la industria de alimentos (confitería, bebidas), la industria cosmetológica y la farmacéutica. De esta manera se puede identificar el proceso de comercialización, distribución e industrialización del rubro como un componente de enlace a través de todo el circuito cacaotero, el cual se inicia con el productor agrícola hasta el consumidor final. Además, el creciente interés en los últimos años por el consumo de alimentos que además de nutrir tengan un impacto favorable en la salud, ha incentivado el estudio de componentes naturales como los polifenoles presentes en plantas y frutos, los cuales han recibido especial atención debido a sus propiedades funcionales como antioxidantes, anticancerígenos, antiinflamatorios, antibacteriales. La comercialización de los granos de cacao de los pequeños agricultores hacia la Cooperativa Agraria Industrial Naranjillo, es muy heterogéneo lo que permite obtener diferentes calidades de productos procesados. En este trabajo de investigación consistió en acentuar si los procesos tecnológicos influyen mucho en el contenido de antioxidantes durante el procesamiento del licor de cacao y polvo de cacao; de allí el interés despertado para realizar la investigación, para ello se plantearon los siguientes objetivos: Cuantificar el contenido de polifenoles totales y antocianinas durante el procesamiento de licor de cacao y polvo de cacao. Cuantificar la capacidad antioxidante durante el procesamiento de licor de cacao y polvo de cacao mediante la capacidad de inhibir radicales 1,1-difenil-2-picrilhidrazil (DPPH) y 2,2-azinobis (3etilbenzotiazolino -6- ácido sulfonico) (ABTS+).

\section{Metodología Experimental}

\section{El muestreo}

El muestreo se realizó en los lotes de productos almacenados de la Planta de la Cooperativa Agraria Industrial Naranjillo, supervisado por el ingeniero de turno, el muestreo fue realizado de modo aleatorio cuyas muestras son grano, grano tostado, grano molido, licor de cacao, polvo de cacao y cocoa- vainilla todas ellas con una cantidad de $1000 \mathrm{~g}$ independientemente.

\section{Acondicionamiento de la muestra}

Los análisis se realizaron después de cada muestreo, los mismos que se hicieron en tres oportunidades. Las muestras fueron tomadas de las diferentes operaciones del proceso de elaboración de licor de cacao y polvo de cacao tal como se presenta en la Figura 1 y se detalla a continuación: Los granos de cacaos fermentados y secos fueron recepcionados con $7,5-10 \%$ de humedad en esta operación se tomó la muestra de granos y se denominó T1 (MP). Las almendras de cacao pasan por un tamiz en vibración quedando atrapados los granos cubiertos con mucilago, el polvo e impurezas. El T2 (TO) se obtuvo de la torrefacción o tostado el cual se realiza a una temperatura de $80-100^{\circ} \mathrm{C} / 30$ - 45 min. reduciendo hasta una humedad 2,5 - 3,0\%. Luego se elimina la cascarilla adherida en el grano tostado. Seguidamente se realiza la molienda, los granos sometidos a una presión entre $38-40 \mathrm{MPa}$ y temperatura entre $18-20^{\circ} \mathrm{C}$ en esta operación se realizó el muestreo T3 (MO). En el homogenizado a una temperatura de $80-100^{\circ} \mathrm{C}$ se obtiene el licor de cacao T4 (LC). El licor de cacao pasa a la prensa cuyo objetivo es separar la manteca del licor de cacao la operación se realiza a una temperatura de 95 a $100^{\circ} \mathrm{C} / 30 \mathrm{~min}$. a una presión de $480 \mathrm{~kg} / \mathrm{cm} 2$. En esta operación se realizó el muestreo T5 (PC). Para obtener cocoas comerciales se mezcla polvo de cacao, azúcar blanca refinada, maicena, canela y clavo de olor. En esta operación se realizó el muestreo T6 (CC).

\section{Preparación del extracto hidroalcoholico}

Las operaciones realizadas para la preparación del extracto para cuantificación de polifenoles totales, antocianinas y actividad antioxidante se muestran en la Figura 2, donde la muestra de grano entero T1 se realizó la limpieza y se efectuó manualmente. El tratamiento T2 provienen de la torrefacción; para realizar el extracto los granos de cacao fueron descascarillados de forma manual, para obtener la almendra. Los tratamientos T3, T4, T5, y T6 parten del molido que tiene por finalidad de reducir el tamaño de partícula para facilitar el proceso de desgrasado, el cual se realizó en un molino 
helicoidal 5-20 micras. El desgrasado se realizó por solvente en frío (Método Folch), que consistió en pesar $20 \mathrm{~g}$ de muestra de cacao molido y macerado por $24 \mathrm{~h}$ en $50 \mathrm{~mL}$ de solvente $(1: 2 \mathrm{v} / \mathrm{v}$. metanol y cloroformo), luego se filtró para separar la torta de la grasa; la torta fue secado en estufa a $45^{\circ} \mathrm{C} / 15 \mathrm{~min}$ para evaporar el solvente.

Equipos: Balanza analítica, estufa.

\section{Métodos de Análisis}

\section{Cuantificación de polifenoles totales}

Se realizó partiendo del extracto hidroalcohólico 100 $\mathrm{mg} / \mathrm{mL}$ (filtrado y centrifugado 10000rpm/10min a $\left.4^{\circ} \mathrm{C}\right)$, a partir de ello se realizó la dilución de trabajo $5 \mathrm{mg} / \mathrm{mL}$, $8 \mathrm{mg} / \mathrm{mL}$ y $10 \mathrm{mg} / \mathrm{mL}$, para el $1 \mathrm{er}$, 2 do y 3er muestreo respectivamente con 5 repeticiones por tratamiento, cabe destacar que se adiciono en los tubos para cada tratamiento $1580 \mu \mathrm{L}$ de agua destilada, $20 \mu \mathrm{L}$ de extracto diluido $(5,8$ y 10 $\mathrm{mg} / \mathrm{mL}$ ), $100 \mu \mathrm{L}$ de fenol Folin Ciocalteu y finalmente $300 \mu \mathrm{L}$ de $\mathrm{Na} 2 \mathrm{CO} 3$ al $20 \%$ y se incubo por $2 \mathrm{~h}$ a temperatura ambiente, luego se hizo la lectura en espectrofotómetro UV/VIS a una longitud de onda de $700 \mathrm{~nm}$. Las absorbancias obtenidas fueron remplazadas en la ecuación de la curva estándar y expresadas en equivalente de ácido gálico ( $g$ EAG/100g muestra). Los resultados fueron analizados mediante el diseño completo al azar (DCA) y diseño bloque completo al azar (DBCA) en los tratamientos donde hubo diferencia estadística se procedió a determinar la prueba de Tukey $\mathrm{P}<0,05$ para ello se utilizó el programa SAS.

\section{Cuantificación de antocianinas}

\section{Preparación de solución buffer}

Para la cuantificación de antocianinas primero se procedió a la preparación de las soluciones buffer. Buffer $\mathrm{pH}=1: 125 \mathrm{~mL}$ de $0,2 \mathrm{M} \mathrm{KCl}$ y $375 \mathrm{~mL}$ de 0,2 $\mathrm{M} \mathrm{HCl}$ y aforarlo a $1 \mathrm{~L}$ con agua desionizada. Buffer $\mathrm{pH}=4,5: 200 \mathrm{~mL}$ de $1 \mathrm{M} \mathrm{CH} 3 \mathrm{COONa}, 120 \mathrm{~mL}$ de $1 \mathrm{M}$ $\mathrm{HCl}$ y $180 \mathrm{~mL}$ de agua desionizada y aforarlo a 1 litro.

\section{Procedimiento de análisis}

Se realizó partiendo del extracto hidroalcohólico 100 $\mathrm{mg} / \mathrm{mL}$, filtrado y centrifugado $10000 \mathrm{rpm} / 10 \mathrm{~min}$. a $4^{\circ} \mathrm{C}$, se trabajó con 5 repeticiones por tratamiento, luego se hizo reaccionar con el buffer de $\mathrm{pH} 1 \mathrm{y} \mathrm{pH}$ 4,5 a $1 \mathrm{~mL}$ para posterior realizar la lectura en el espectrofotómetro UV/VIS a una longitud de onda de $510 \mathrm{~nm}$.

Capacidad de inhibir radical libre 1,1-difenil-2picrilhidrazil (DPPH)

Se preparó $10 \mathrm{~mL}$ de solución stock de DPPH a $1 \mathrm{mM}$ en metanol al $99 \%$ de pureza, se agito hasta la solubilización completa del compuesto y se almaceno a $4^{\circ} \mathrm{C}$ protegido de la luz. A partir de esta solución stock se preparó $50 \mathrm{~mL}$ de DPPH a $20 \mu \mathrm{M}$ en metanol al $99 \%$ de pureza. Para la inhibición del radical DPPH en las distintas muestras se realizó el filtrado y centrifugado $10000 \mathrm{rpm} / 10 \mathrm{~min}$. a $4^{\circ} \mathrm{C}$, a partir de ello se prepararon soluciones de trabajo de: $15,30,60,120 \mu \mathrm{g} / \mathrm{mL}$. Luego en una cubeta de poliestireno se adiciono $25 \mu \mathrm{L}$ de la solución trabajo y $975 \mu \mathrm{L}$ de solución DPPH a $100 \mu \mathrm{M}$, se realizó la lectura en un espectrofotómetro de UV/VIS a una longitud de onda de $517 \mathrm{~nm}$ con un tiempo de 30 $\min$.

Capacidad de inhibir radical libre 2,2-azinobis (3etilbenzotiazolino -6-ácido sulfonico) $\left(A B T S^{\circ}+\right)$

El radical $A B T S^{\circ}+$ se forma tras la reacción de $A B T S$ $(7 \mathrm{mM})$ con persulfato potásico $(140 \mathrm{mM}$, concentración final) incubados a temperatura ambiente y en oscuridad durante 16h. Una vez formado el radical $\mathrm{ABTS}^{\circ}+$ se diluyo con metanol hasta obtener un valor de absorbancia entre 0,7 a 1,2. Para la inhibición del radical ABTS en las distintas muestras se realizó el filtrado y centrifugado $10000 \mathrm{rpm} / 10 \mathrm{~min}$. a $4^{\circ} \mathrm{C}$, a partir de ello se prepararon soluciones de trabajo de: $5,40,70,95$ $\mu \mathrm{g} / \mathrm{mL}$. Luego en una cubeta de poliestireno se adicionó $10 \mu \mathrm{L}$ de la solución de trabajo y $990 \mu \mathrm{L}$ del radical $A B T S$. La disminución de la absorbancia se registró a $734 \mathrm{~nm}$ por espacio de 10 minutos.

\section{Análisis de multivariado - componentes principales}

Es una técnica que intuitivamente sirve para hallar las causas de la variabilidad de un conjunto de datos y ordenarlas por importancia, en tal sentido para evaluar el comportamiento de los polifenoles totales, antocianinas, actividad antioxidante (DPPH y $\mathrm{ABTS}^{\circ}+$ ) y poder reducir la dimensionalidad de los conjuntos de datos se utilizó el programa InfoStat versión 2011.

\section{Equipos:}

Espectrofotómetro modelo Genesys 6 (Thermo Electrón Corporation) SN 2M6G261002. 
Balanza analítica modelo ESJ-210-4 (Digital precisión), capacidad $200 \mathrm{~g}$ y modelo Adventurer Pro AV114 (OHAUS) capacidad $110 \mathrm{~g}$.

Estufa modelo ODH6- 9240A (TOMOS Heatring Drying Oven).

Congelador FFV-2065FW $-20^{\circ} \mathrm{C}$ (Frigidaire, USA).

Homogenizador modelo VORTEX GENIE-2

(Scientific industrias. SITM).

Centrifuga modelo MIKRO 22R (Hettich).

$\mathrm{pH}$ - metro (Mettler Toledo SevenEasy) $\mathrm{pH} 0-14, \mathrm{~T}^{\circ}$ $0-100^{\circ} \mathrm{C}$ SN 8513902.

\section{Resultados y discusión}

Cuantificación de polifenoles totales en los diferentes lotes de muestreo.

En el Tabla 1, en ella se puede apreciar que entre los lotes se encontró diferencia estadística significativa $(P \leq 0,05)$, los lotes 1 y 2 presentaron el mismo valor estadístico 5,406 $\pm 0,202 \mathrm{~g} \mathrm{EAG/100} \mathrm{g}$ y $5,675 \pm 0,145 \mathrm{~g}$ EAG/100 $\mathrm{g}$ y el lote de muestreo diferente fue el tercero 4,871 $\pm 0,135 \mathrm{~g} \mathrm{EAG} / 100 \mathrm{~g}$.

Tabla 1: Contenido de polifenoles totales en los diferentes lotes de muestreo.

\begin{tabular}{lll}
\hline Lote de muestreo & $\begin{array}{l}\text { g EAG/100g de } \\
\text { muestra }\end{array}$ \\
\hline 1ro & $5,406 \pm 0,202 \mathrm{a}$ \\
2do & $5,675 \pm 0,145 \mathrm{a}$ \\
3er & $4,871 \pm 0,135 \mathrm{~b}$ \\
\hline
\end{tabular}

Los valores representan (promedio \pm SEM) datos provienen del experimento $(n=5)$ valores de la misma columna con superíndices diferentes son significativos $(p \leq 0,05)$.

La presencia de polifenoles en el grano de cacao es dependiente de varios factores como la madurez, variedades de cacao, reacciones químicas, procesamiento, almacenamiento. Así como también la fermentación y el secado de granos de cacao y el tratamiento de poscosecha. [1]

Cuantificación de polifenoles totales en las etapas de procesamiento del licor de cacao y polvo de cacao.

Los resultados se presentan en la Figura 1, el mayor contenido de polifenoles totales fue para los granos $6,394 \pm 0,095 \mathrm{~g}$ EAG/100 $\mathrm{g}$ de muestra y el menor correspondió a granos molidos 4,036 \pm 0,105 g EAG/100 g de muestra. De los resultados encontramos que el grano tuvo el mayor contenido de polifenoles totales comparado al resto de tratamientos. El contenido de polifenoles totales en granos de cacao no fermentados y secados de diferentes países es variable, Costa de Marfil variedad Forastero $8,15 \pm 1,82 \mathrm{~g} E A G / 100 \mathrm{~g}$, Colombia variedad Amazon 8,14 \pm 0,37 g EAG/100 g, Ecuador variedad Amazon, Trinitario, Canelo y Amazon híbrido 8,42 $\pm 0,87 \mathrm{~g}$ EAG/100 g, Venezuela variedad Trinitario 6,43 $\pm 0,56 \mathrm{~g}$ EAG/100g, y Perú

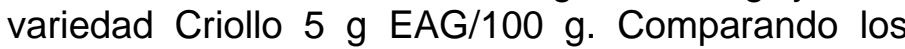
resultados según las etapas de proceso entre el grano y granos tostado podemos apreciar que el tostado afecta el contenido de polifenoles totales en un $20,5 \%$ (grano sin tostar $6,394 \pm 0,095 \mathrm{~g} \mathrm{EAG/100}$ $\mathrm{g}$ de muestra y grano tostado $5,081 \pm 0,287 \mathrm{~g}$ EAG/100 g de muestra). [2] Reporta pérdidas durante el proceso de pre tostado $100^{\circ} \mathrm{C}$ y tostado $130^{\circ} \mathrm{C}$ está en un rango de 32,6 a 54,7\%, atribuyendo esta tendencia al efecto de la temperatura y a la posible formación de otros compuestos en la reacción de Maillard. Comparando el contenido de polifenoles entre el grano y grano molido tenemos que el contenido de polifenoles decreció en $36,88 \%$. [1]

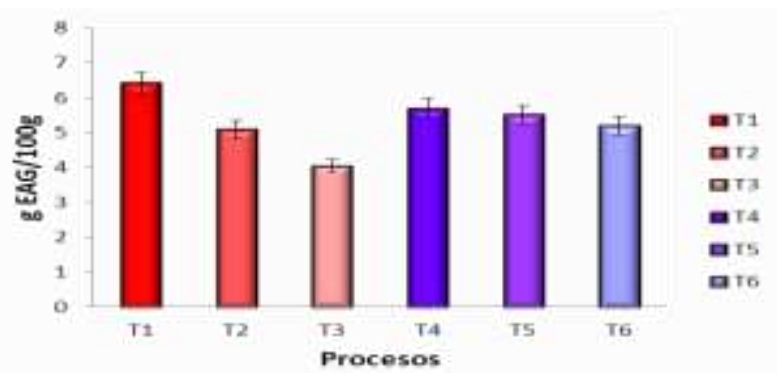

Figura 1: Representación del contenido de polifenoles totales en las etapas de proceso de licor de cacao y polvo de cacao.

Con respecto al licor de cacao podemos apreciar que el contenido comparado al grano molido aumenta en esta operación (grano molido 4,036 \pm $0,105 \mathrm{~g}$ EAG/100 g de muestra y licor de cacao $5,689 \pm 0,153 \mathrm{~g} \mathrm{EAG} / 100 \mathrm{~g}$ de muestra), al moler los trozos de cacao se convierte en licor de cacao, en esta etapa las paredes celulares se destruyen y el calor de fricción que se desarrolla por la molienda funde los glóbulos de grasa, los cambios en su mayoría son físicos incluyendo la eliminación de agua, el licor debe molerse a suficiente finura para desprender la grasa y debe ser lo bastante grueso para no causar dificultades en el prensado [3]. El contenido de polifenoles en licor de cacao varía de acuerdo al país de origen. [4] Reporta en tres 
muestras de cacao en polvo CP-1 6,020 $\pm 4,54$, CP$24,530 \pm 1,16$ y CP-3 5,170 $\pm 0,57 \mathrm{~g} \mathrm{EAG} / 100 \mathrm{~g}$ de muestra, los resultados reportados en la investigación se encuentran dentro del rango publicado. [5]

En general de todos los resultados los polifenoles son afectados por el genotipo, origen geográfico, método de fermentación y tamaño de poda. [6]

\section{Cuantificación de antocianinas en los diferentes lotes de muestreo}

Los resultados se muestra en el Tabla 2, en ella se puede apreciar que entre los lotes se encontró diferencia estadística significativa $(P \leq 0,05)$, los lotes 1 y 2 presentaron el mismo valor estadístico $0,419 \pm 0,101 \mathrm{mg}$ cianidina-3-glucósido/g de muestra y 0,404 \pm 0,099 mg cianidina-3-glucósido/g de muestra y el lote de muestreo diferente fue el tercero $0,332 \pm 0,078 \mathrm{mg}$ cianidina-3-glucósido/g de muestra.

Tabla 2: Contenido de antocianinas totales en los diferentes lotes de muestreo.

\begin{tabular}{ll}
\hline Lote de muestreo & $\begin{array}{l}\text { mgcianidina-3-glucósido/g } \\
\text { de muestra }\end{array}$ \\
\hline 1ro & $0,419 \pm 0,101 \mathrm{a}$ \\
2do & $0,404 \pm 0,099 \mathrm{a}$ \\
3er & $0,332 \pm 0,078 \mathrm{~b}$ \\
\hline
\end{tabular}

Los valores representan (promedio \pm SEM) datos provienen del experimento $(n=5)$ valores de la misma columna con superíndices diferentes son significativos $(p \leq 0,05)$.

En el proceso de elaboración de licor de cacao, cocoa y chocolates se combinan granos en varias proporciones con especificaciones económicos y estándares de calidad que son los responsables del aroma y propiedades funcionales de los productos. [7] Reportan que la cianidina-3-glucósido da el mayor poder radical lo que confiere la mayor capacidad antioxidante. [8]

Cuantificación de antocianinas en las etapas de procesamiento del licor de cacao y polvo de cacao.

El resultado se presenta en la Figura 2, podemos indicar que entre los tratamientos existió diferencia estadística significativa, se tiene que el mayor contenido de antocianinas fue en el grano 1,49 \pm 0,043 mg cianidina-3-glucósido/g de muestra. El grano fresco de cacao contiene pigmentos de antocianinas de color purpura, cyanidins-3- $\beta$ - galactosyl y cyanidins-3- $\alpha$-L-arabinosyl y durante la fermentación estos pigmentos son hidrolizados por glucosidos resultando un cambio del cotiledón de violeta a marrón. [9]

Reportaron sobre el proceso de fermentación en granos sin fermentar $12 \mathrm{mg}$ cianidina-3-glucósido/g y 1,72 mg cianidina-3glucósido/g en almendras fermentadas, según la información reportada, podemos decir que las antocianinas se degradan durante el proceso de fermentación. Durante el proceso de tostado el contenido de antocianinas disminuyó en $91,8 \%$ comparando al grano sin tostar, esto puede deberse a que en el proceso de tostado los granos son sometidos a $100-120^{\circ} \mathrm{C} / 20-30$ minutos hasta obtener una humedad de $1,5 \%$. [10]

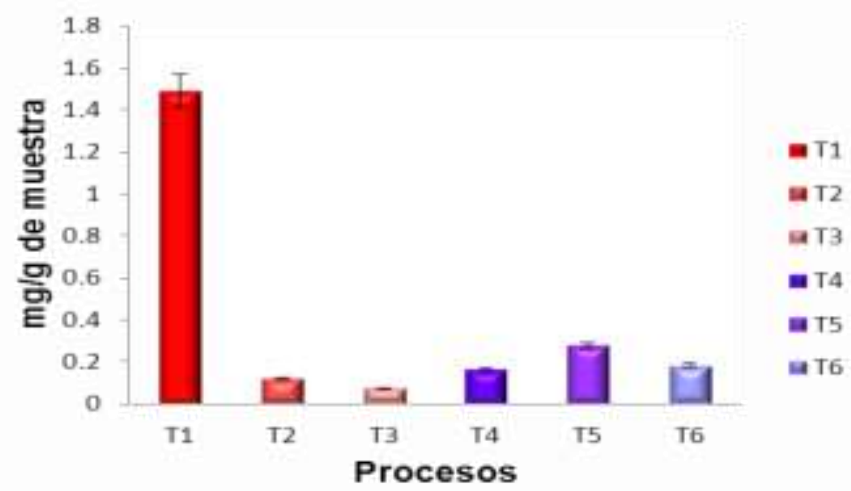

Figura 2: Representación del contenido de antocianinas en las etapas de proceso de licor de cacao y polvo de cacao.

El incremento de la temperatura provoca la pérdida del azúcar glicosilante en la posición 3 de la molécula de apertura de anillo con la consecuente producción de chalconas incoloras. Comparando todos los tratamientos el menor contenido de antocianinas correspondió al grano molido 0,074 \pm 0,003 mg cianidina-3-glucósido/g, comparando este resultado con el grano tostado este ha perdido $39,3 \%$ de antocianinas, al respecto podemos indicar que en esta operación la molienda se realizó 70$80^{\circ} \mathrm{C}$ hasta obtener una finura $97-99 \%$. [11]

La pérdida de antocianina puede deberse a que son muy inestables y se degradan ante algunos factores como la temperatura ya que no deben exceder los $40{ }^{\circ} \mathrm{C}$. El licor de cacao y cocoa-vainilla estadísticamente son los que tuvieron un contenido de antocianinas similares. Para el licor de cacao el contenido fue $0,162 \pm 0,017 \mathrm{mg}$ cianidina-3glucósido/g, este resultado indica que en la molienda ocurren cambios físicos y químicos, pues se elimina el agua, se da la afirmación del sabor y la rotura de 
las células de grasa. [3] Con respecto a la cocoavainilla el contenido fue $0,182 \pm 0,017 \mathrm{mg}$ cianidina3 -glucósido/g. En productos como chocolate con azúcar, chocolate con clavo y canela, y sucedáneo de cacao presentan valores inferiores en el contenido de polifenoles esto puede ser debido a que estos productos son fabricados con cocoa y grasa vegetal y tienen $30 \%$ de licor de cacao. [13]

Coeficiente de inhibición IC50 del radical 1,1diphenyl-2-picrylhidrazil (DPPH) en los diferentes lotes de muestreo.

Los resultados del IC50 se presentan en el Tabla 3, como podemos apreciar entre los tratamientos no existió diferencia significativa, los resultados variaron IC50 53,044 \pm 0,507 a 54,029 $\pm 0,442 \mu \mathrm{g} / \mathrm{mL}$.

Tabla 3: Resultados del IC50 del radical DPPH en los diferentes lotes de muestreo.

\begin{tabular}{ll}
\hline Lote de muestreo & $\mathrm{IC} 50(\mu \mathrm{g} / \mathrm{mL})$ \\
\hline 1ro & $53,044 \pm 0,507 \mathrm{a}$ \\
2do & $53,344 \pm 0,445 \mathrm{a}$ \\
3er & $54,029 \pm 0,442 \mathrm{a}$ \\
\hline \hline
\end{tabular}

Los valores representan (promedio \pm SEM) datos provienen del experimento $(n=5)$ valores de la misma columna con superíndices diferentes son significativos $(p \leq 0,05)$.

Indican que los productos de chocolatería se preparan a partir de granos selectos y combinados que cumplan la certificación de los estándares de calidad y especificación económica. [9]

Coeficiente de inhibición IC50 del radical 1,1diphenyl-2-picrylhidrazil (DPPH) en las etapas de procesamiento del licor de cacao y polvo de cacao.

En la Figura 3, se presenta los resultados del IC50 y se encontró diferencia estadística significativa $(P \leq 0,05)$, podemos indicar que la mayor actividad antioxidante se encontró en las etapas de grano molido (IC50 51,158 $\pm 0,117 \mu \mathrm{g} / \mathrm{mL}$ ), grano (IC50 $52,318 \pm 0,085 \mu \mathrm{g} / \mathrm{mL}$ ), polvo de cacao (IC50 52,743 $\pm 0,528 \mu \mathrm{g} / \mathrm{mL}$ ) y licor de cacao (IC50 52, $930 \pm$ $0,340 \mu \mathrm{g} / \mathrm{mL}$

El grano tuvo buena actividad antioxidante, reportó en granos de cacao criollo IC50 43,041 $\pm 0,16 \mu \mathrm{g} / \mathrm{mL}$ y en CCN-51 IC50 52,493 $\pm 0,29 \mu \mathrm{g} / \mathrm{mL}$. [14] Según los resultados el grano molido tuvo la mayor actividad antioxidante numéricamente (IC50 51,158 $\pm 0,117 \mu \mathrm{g} / \mathrm{mL}$ ), esto puede deberse a que las muestras molidas y tamizadas con mallas entre 460 a $600 \mu \mathrm{m}$ tuvieron mejor valor de capacidad antioxidante. [15] indica que la molienda afecta el color, aceite y los compuestos fenólicos relacionando con el rompimiento de la piel y existe mayor liberación de fitoquímicos en el caso de aceitunas. [16] El IC50 del licor de cacao (52,930 \pm $0,340 \mu \mathrm{g} / \mathrm{mL}$ ) fue estadísticamente igual al grano entero, grano tostado molido y polvo de cacao.

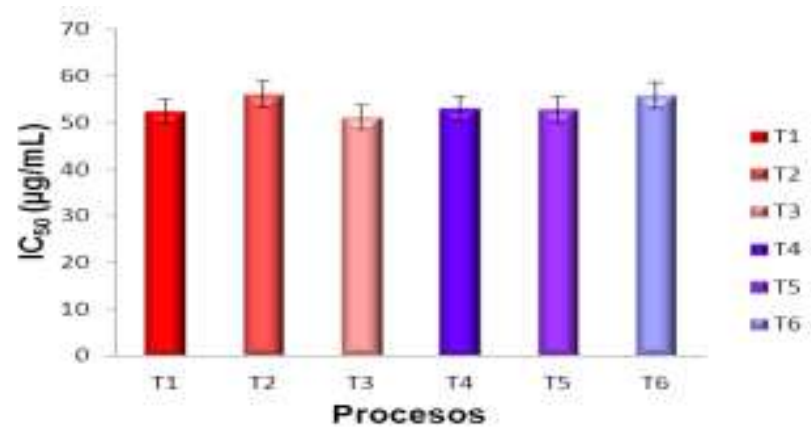

Figura 3: Comportamiento del IC50 con el radical $\mathrm{DPPH}$ en las diferentes etapas de proceso de licor de cacao y polvo de cacao.

El polvo de cacao también tuvo buena actividad antioxidante IC50 52,743 $\pm 0,528 \mu \mathrm{g} / \mathrm{mL}$, comparando este resultado con licor de cacao fueron similares estadísticamente, compara la actividad antioxidante de productos de chocolatería, licor de cacao IC50 DPPH $1,68 \mathrm{mg} / \mathrm{mL}$, el polvo de cacao $7,11 \mathrm{mg} / \mathrm{mL}$ y en chocolate con leche $17,31 \mathrm{mg} / \mathrm{mL}$; cómo podemos apreciar el licor tuvo el mayor valor, pero en el chocolate la actividad antioxidante decae. Los resultados del grano tostado y cocoa-vainilla fueron estadísticamente similares y tuvieron la menor eficiencia frente al radical DPPH comparado a los otros tratamientos. [17] En los granos de cacao tostado se reportó IC50 55,986 $\pm 0,599 \mu \mathrm{g} / \mathrm{mL}$, indican que la capacidad antioxidante puede ser afectada por muchos factores como el tostado, proceso de fermentación por que en estas etapas decrece el contenido de flavonol en los granos de cacao. [5] Reportó en granos tostado criollo IC50 $47,437 \mu \mathrm{g} / \mathrm{mL}$ y catequina $545,336 \mathrm{mg} \mathrm{CAT} / \mathrm{kg}$ y en CCN-51 IC50 52,716 $\mu \mathrm{g} / \mathrm{mL}$ y catequina $654,046 \mathrm{mg}$ CAT/kg. [14] Comparando con nuestros resultados estos datos tienen semejanza. Con respecto a la cocoa-vainilla tuvo un valor de IC50 55,700 $\mu \mathrm{g} / \mathrm{mL}$, en polvo de cacao reporta un IC50 $1,68 \mathrm{mg} / \mathrm{mL}$, en chocolate negro IC50 $7,04 \mathrm{mg} / \mathrm{mL}$, en chocolate con leche IC50 17,31 mg/mL como podemos apreciar cuando se trabaja productos de chocolatería la actividad antioxidante disminuye. [17] 
Coeficiente de inhibición IC50 del radical 2,2azinobis (3-etilbenzotiazolino -6- ácido sulfónico) (ABTS) en los diferentes lotes de muestreo.

De los resultados sobre los lotes de muestreo presentados en la Tabla 5, podemos apreciar que entre los tratamientos se encontró diferencia estadística significativa $(P \leq 0,05)$, encontramos que el segundo lote $(41,799 \pm 0,764 \mu \mathrm{g} / \mathrm{mL})$ presento una menor capacidad antioxidante frente al radical ABTS caso que no sucedió con el radical DPPH, esto puede deberse a que ambos radicales tienen medidas diferentes de los compuestos antioxidantes. El ABTS mide la actividad de compuestos de naturaleza hidrofílica y lipofílica, la mayoría de antioxidantes naturales son multifuncionales por lo que no pueden ser evaluados con un solo método. [15]

Tabla 5: Resultados del IC50 del radical ABTS en los diferentes lotes de muestreo.

\begin{tabular}{ll}
\hline Lote de muestreo & $\mathrm{IC} 50(\mu \mathrm{g} / \mathrm{mL})$ \\
\hline 1ro. & $35,998 \pm 0,545 \mathrm{~b}$ \\
2do & $41,799 \pm 0,764 \mathrm{a}$ \\
3ero & $35,799 \pm 0,179 \mathrm{~b}$ \\
\hline \hline
\end{tabular}

Los valores representan (promedio \pm SEM) datos provienen del experimento $(n=5)$ valores de la misma columna con superíndices diferentes son significativos $(p \leq 0,05)$.

Por otro lado, esta diferencia puede deberse a que en el procesamiento ingresan lotes de diferentes agricultores como se puede saber en la zona las áreas de cultivo que tiene un productor de cacao es pequeño y la planta de procesamiento para un turno utiliza aproximadamente $8 \mathrm{t}$.

Coeficiente de inhibición IC50 del radical 2,2azinobis (3-etilbenzotiazolino -6- ácido sulfónico) (ABTS) en las etapas de procesamiento del licor de cacao y polvo de cacao.

Según los resultados presentados en la Figura 4, referido al comportamiento del IC50 del radical ABTS podemos indicar que entre las etapas de muestreo se encontró diferencia estadística significativa $(P \leq 0,05)$.

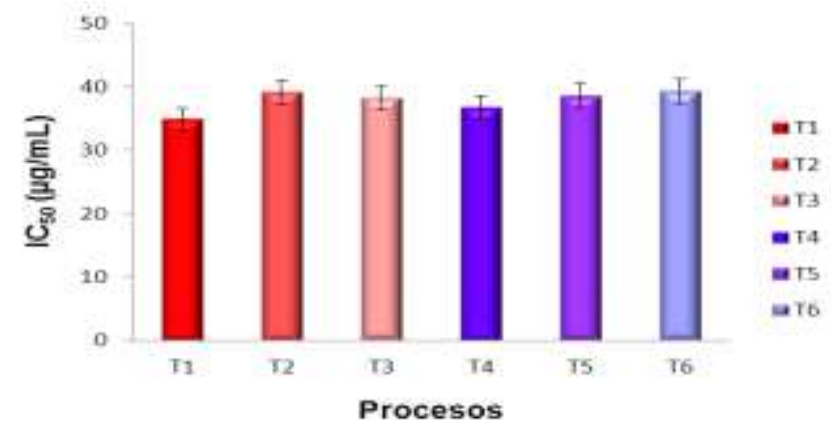

Figura 4: Comportamiento del IC50 con el radical ABTS en las diferentes etapas de proceso.

El grano de cacao tuvo la mayor capacidad antioxidante frente a este radical (IC50 34,918 $\mu \mathrm{g} / \mathrm{mL}$ ). Indican que el grano de cacao ha atraído atención debido al alto contenido de polifenoles que estos a su vez tienen efectos beneficiosos para la salud humana por las propiedades antioxidantes relativamente altas. Los resultados de las muestras ordenadas de acuerdo a la actividad antioxidante fue licor de cacao IC50 36,850 $\mathrm{gg} / \mathrm{mL}$, grano molido IC50 $38,279 \mu \mathrm{g} / \mathrm{mL}$ y polvo de cacao IC50 38,639 $\mu \mathrm{g} / \mathrm{mL}$. [7]

Indican que el licor de cacao es la materia principal para la producción de chocolate y es un factor crucial en determinar la característica sensorial y los valores alimenticios del chocolate, la composición de esta depende de la variedad del grano, de los procesos de poscosecha, y condiciones de tostado. La menor capacidad antioxidante lo presento el grano tostado IC50 $39,183 \pm 0,339 \mu \mathrm{g} / \mathrm{mL}$ y cocoavainilla IC50 $39,323 \pm 1,439 \mu \mathrm{g} / \mathrm{mL}$ comparando estos resultados con respecto al grano podemos indicar que en el tostado se perdió $12,2 \%$ y en la cocoa-vainilla $12,6 \%$ de capacidad antioxidante. [7] Reporta para tostado $274,40 \pm 37,41 \mathrm{mmol}$ TROLOX/kg y para cocoa con grasa vegetal $51,42 \pm$ $16,57 \mathrm{mmol}$ TROLOX/kg, realizando la misma comparación con respecto al grano en el tostado pierde $24 \%$ y en la cocoa $85,8 \%$. [13]

\section{Conclusiones}

El mayor contenido de polifenoles totales se encuentra en granos de cacao 6,394 \pm 0,095 g EAG/100 $\mathrm{g}$ de muestra y el menor en granos tostados y molidos 4,036 $\pm 0,105 \mathrm{~g}$ EAG/100 g de muestra. Los contenidos de antocianinas en las etapas de procesamiento del licor y polvo de cacao estuvieron entre 1,490 $\pm 0,043$ a 0,074 $\pm 0,003 \mathrm{mg}$ cianidina-3-glucósido/g de muestra.

La mayor capacidad antioxidante frente al radical 
DPPH correspondió al grano molido IC50 51,158 \pm $0,117 \mu \mathrm{g} / \mathrm{mL}$ (IAA $0,762 \pm 0,002)$ y la menor capacidad antioxidante fue para el grano tostado IC50 55,986 $\pm 0,599 \mu \mathrm{g} / \mathrm{mL}$ (IAA 0,698 $\pm 0,007$ ) y la cocoa-vainilla IC50 55,700 $\pm 0,805 \mu \mathrm{g} / \mathrm{mL}$ (IAA $0,702 \pm 0,010)$. La mayor capacidad antioxidante frente al radical ABTS correspondió al grano IC50 $34,918 \pm 0,054 \mu \mathrm{g} / \mathrm{mL}$ y la menor capacidad antioxidante fue para el grano tostado IC50 39,183 \pm $0,339 \mu \mathrm{g} / \mathrm{mL}$ y la cocoa-vainilla IC50 39,323 $\pm 1,439$ $\mu \mathrm{g} / \mathrm{mL}$. El contenido de polifenoles totales, antocianinas y capacidad antioxidante varía en las etapas de procesamiento de licor de cacao y polvo de cacao.

\section{Agradecimientos}

A la Universidad Nacional Agraria de la Selva, por ser el alma mater donde culmine mi carrera profesional.

A la Cooperativa Agraria Industrial Naranjillo por haberme proporcionado el material de trabajo y por ser partícipe del trabajo de investigación.

A la Dra. Elizabeth Susana Ordoñez Gómez, por su valiosa orientación como patrocinadora de la tesis. A mi madre: SUNILDA EDALZEIN RIVERA GARCIA, mi más profundo agradecimiento y eterna gratitud por ser mi guía y mostrar siempre una imagen de perseverancia ante toda circunstancia esquiva a nuestra realidad.

\section{Referencias}

[1] M. Arlorio, M. Locatelli, F. Travaglia, J. Coisson, E. Del Groso, A. Minassi, G. Appendino, A. MARTELLI 2008. Roasting impact on the contents of clovamide (Ncaffeoyl-L-DOPA) and the antioxidant activity of cocoa beans (Theobroma cacao L). Food Chemistry. Novara, Italy 106:967-975.

[2] F. A. Tomás Barberan; E. Cienfuegos Jovellanos; Marin, A.; B. Muguerza, A. gilizquierdo; B. Cerdá; P. Zafrilla; J. Morillas; J. Mulero, A. Ibarra; M. A. Pasamar, D. Ramon y J. Espin (2007). A new process to develop a cocoa powder wiht higher flavonoid monomer content and enhanced bioavailability in healthy humans. J. Agric. Food Chem. Valencia, España. 55(10):3926-3935.

[3] N. Desrosier 1985. Elementos de tecnología de alimentos. 3 ed. México, CECSA. 783 p.
[4] A. Othman, A. Ismail, N. Ghani, I. Adenan (2007). Antioxidant capacity and phenolic content of cocoa beans. FoodChemistry. Kuala Lumpur, Malaysia. 100:1523-1530 p.

[5] K. Miller, J. Apgar, D. Sweigart, A. Stuart, N. Mchale, M. Kondo, W. Hurst (2009). Preservation of cocoa antioxidant activity, total polyphenols, flavan-3-ols, and procyanidinconten in foods prepared with cocoa powder. Journal of FoodScience. USA. 74(6):398-404.

[6] L. Stahl, K. Miller, J. Apgar, D. Sweigart, D. Stuart, N. Mchale, B. Ou, M. Kondo, y W. Hurst (2009). Preservation of cocoa antioxidant activity, total polyphenols, flavan3-ols, and procyanidin content in foods prepared with cocoa powder. J of Food Science.EEUU. 74(6):456-461.

[7] I. Radojcic, K. Delonga, E. Mazor, V. Dragovic-Uzelac, M. Caric, J. Vorkapic-Furac (2009). Polypehnolic content and composition and antioxidative activity of different cocoa liquors.Czech j. Food Sci.Zagreb, Croacia.27 (5):330-337.

[8] B. Winkel, Shirley (2001). Flavonoid biosinthesis. A colorful model for genetics, biochemistry, cell biology and biotechnology. Plan Physiol. Virginia, EEUU. 126(2):485493.

[9] N. Niemenak, C. Rohsius, S. Elwers, D. Omokolo, R. Lieberei (2006). Comparative study of different cocoa (Theobroma cacao L.) clones in terms of their phenolics and anthocyanins contents.Journal of food composition and analysis. Hamburgo, Alemania. 19:612-619.

[10] E. Cubero, G. Enriquez, A. Hernandez, y T. Rodriguez (1992). Quality of cocoa in four cacao growing zones of Costa Rica.Turrialba. San Jose. vol. 42(3): $287-293$.

[11] G. G. Astrid 2008. Las antocianinas como colorantes naturales y compuestos bioactivos. Universidad Nacional de Colombia, departamento de química. Bogotá, Colombia. 13(3):27-36.

[12] B. M. Ceron (2008). Extracción, caracterización y estabilidad de antocianinas y otros compuestos antioxidantes obtenidos a partir de la zarzamora. Tesis profesional ingeniera química y alimentos. Puebla, México. Universidad de la Américas. $70 \mathrm{p}$.

[13] V. Perea, C. Cadena, A. Herrera (2009). El cacao y sus productos como fuente 
de antioxidantes: Efecto del procesamiento. Revista de la Universidad Industrial de Santander. Salud. Bucaramanga, Colombia.41(2):120-126.

[14] M. Huanca, J. A. (2010). Polifenoles totales, catequina y actividad antioxidante en granos de cacao (Theobroma cacao L.) Criollo y CCN-51 en las etapas de beneficio y tostado. Tesis ing. Ind. Alim. Tingo María, Perú. Universidad Nacional Agraria la Selva. 80p.

[15] V. Ovaco, LL. Pineda (2011). Los residuos de cacao (Theobroma cacao L.) como fuente alternativa de antioxidantes. Tesis Ing. Industrias Agropecuarias. Loja, Ecuador. Universidad Católica de Loja. 42p.

[16] J. Tovar de Dios (2001). Estudio del efecto de la aplicación de diferentes estrategias de riego al olivo (Olea europea L.) de la variedad arbequina sobre la composición del aceite. Tesis de Doctora. Lleida, España. Universidad de Lleida. 177 p.

[17] C. Hii, C. Law, S. Suzannah, M. Misnawi and Cloke (2009). Polyphenols in cocoa (Theobroma cacao L.). As. J. Food Ag. Ind. Bangkok, Thailandia. 2(4):702-722.
E-mail: chavezruc@hotmail.com 